\title{
The QEYSSAT mission: on-orbit demonstration of secure optical communications network technologies (Erratum)
}

A. Scott, T. Jennewein, J. Cain, I. D'Souza, B. Higgins, et al.

A. Scott, T. Jennewein, J. Cain, I. D'Souza, B. Higgins, D. Hudson, H. Podmore, W. Soh, "The QEYSSAT mission: on-orbit demonstration of secure optical communications network technologies (Erratum)," Proc. SPIE 11532, Environmental Effects on Light Propagation and Adaptive Systems III, 115320Q (11 November 2020); doi: 10.1117/12.2589489

SPIE. Event: SPIE Remote Sensing, 2020, Online Only 


\section{The QEYSSAT mission: on-orbit demonstration of sec ure optic al communic ations network tec hnologies (Enatum)}

A. Scott, ${ }^{1}$ T. Jennewein, ${ }^{2}$ J. Cain, ${ }^{1}$ I. D'Souza, ${ }^{1}$ B. Higgins, ${ }^{2}$ D. Hudson, ${ }^{1}$ H. Podmore, ${ }^{1}$ W. Soh ${ }^{1}$

${ }^{1}$ Honeywell Aerospace (Canada)

¿Univ. of Waterloo (Canada))

Proceedings Volume 11532, Environmental Effects on Light Propagation and Adaptive Systems

III; 115320H (2020) https://doi.org/10.1117/12.2574154

Event: SPIE Remote Sensing, 2020, Online Only

Online Publication Date: 20 September 2020

Enatum Published: 11 November 2020

A revised version of this manuscript was published on 24 April 2019. Details of the revision are provided in the text that accompanies this Erratum. The original paper has been updated.

The original version of the paper omitted two contributing a uthors (. . Ca in and B. Higgins). After receiving statements from both stating they had contributed to and reviewed the paper prior to public ation, they were added to the author list. 